\title{
Effect of Pre-Deformation on Fracture Behavior Transition due to Strain-Rate Change in Fe-5\%Si Alloy
}

\author{
by \\ Takashi Mizuguchi ${ }^{*}$, Ryota Oouchi ${ }^{* *}$ and Yasuhiro TANAKA ${ }^{* *}$
}

\begin{abstract}
Fracture behavior transition due to strain rate change in Fe-5\% Si alloy with dislocation microstructures was studied to investigate the effect of pre-deformation on toughness. The Fe-5\% $\mathrm{Si}$ alloy was multi-passed rolled (pre-deformed) at $1073 \mathrm{~K}$ to various reductions up to $50 \%$ to introduce dislocation microstructure. The room temperature tensile deformation was conducted at various strain rates from $10^{-5}$ to $10^{0} / \mathrm{s}$. Electron backscattering diffraction measurements clarified that the dislocations were successfully introduced within the grains. All rolled alloys were fractured with local elongation (necking) at slower strain rate. When strain rate was faster, the local elongation disappeared and the fracture manner was turned to brittle. The strain rate at which fracture behavior changed increased with increasing of the reduction. On the other hand, the almost fully recrystallized Si steel was fractured in the brittle manner at any strain rate and the transition strain rate was not found. The fractured tensile specimen with no local elongations contains deformation twins ; however, these deformation twins were not observed in the fractured specimen with local elongations. This result indicates that the dislocation structure evolved during rolling suppressed the twinning and that the dislocation structure is effective for the enhancement of both ductility and toughness in Fe-5\%Si alloy.
\end{abstract}

Key words : Magnetic steel sheet, Ductile-brittle transition, Deformation twin, Strain rate, Dislocation structure, Pre-strain

\section{Introduction}

Fe-Si steels containing 1.5-3.5 mass\% $\mathrm{Si}$ are widely used in magnetic steel sheet production. Magnetic steel sheets with more appropriate magnetic and mechanical properties are required to prevent global warming. The soft magnetic property of Si steel sheets is improved by increasing the Si content. ${ }^{1{ }^{1,2)}}$ However, workability is dramatically reduced and brittle-like fractures are likely to occur. Therefore, it is important to understand the brittle fracture behavior of Fe-high Si steels containing more than $3.5 \% \mathrm{Si}$ and to reduce their brittleness. Previous studies ${ }^{3), 4}$ have focused on the ductile-brittle transition temperature (DBTT) of Fe-Si alloys, which is the toughness benchmark. If the fracture process is controlled by thermally activated motion of dislocation, we can correlate temperature with strain rate, which is a possible parameter alternative to temperature. In other words, low temperature deformation is equivalent to high strain rate deformation, implying that a ductile-brittle transition due to strain rate changes can be predicted. Magnetic steel sheets are used at ambient temperature and are produced by rolling to obtain a particular strain rate. It has been reported that (1) Fe-high Si alloys show a fracture behavior transition due to strain-rate changes, (2) the toughness of $\mathrm{Si}$ steel can be evaluated using fracture behavior transition due to strain-rate changes ${ }^{5), 6}$ and (3) brittle fracture is closely related with the existence of deformation twins. ${ }^{4) ~ 8)}$ In other words, the suppression of deformation twinning is important to improve the brittleness of Si steel.

The suppression of twinning in $\mathrm{Fe}^{\text {9) 13) }}$ and $\mathrm{Fe}-\mathrm{Si}$ alloy ${ }^{4)}$ by small amount of pre-deformation has been reported by various researchers. For example, Narita et al. ${ }^{4)}$ reported dislocation substructures such as sub-boundary and mobile dislocations introduced by the pre-deformation improved the ductility of Fe-Si alloy. This means that deformation microstructure suppresses the brittle fracture. Uenishi et al. ${ }^{14)}$ and Aronsson et. al. ${ }^{15)}$ investigated stress-strain behaviors of Si steels; however, there has been no systematic study of the effect of pre-deformation and strain rate on fracture behavior. This study aims to clarify the fracture behavior in Fe-high Si alloy using the room temperature tensile tests at wide range of strain rates $\left(10^{-5}\right.$ to $\left.10^{0} / \mathrm{s}\right)$ to clarify the effect of pre-deformation on the fracture behavior due to strain rate change.

\section{Experimental Procedure}

Fe-5mass\%Si alloy with hot rolled ferritic microstructure with the thickness of $15 \mathrm{~mm}$ was prepared by the furnace melting method. The chemical composition of Fe$5 \% \mathrm{Si}$ alloy used in this study is shown in Table 1 . This alloy ingot was multi-pass rolled (pre-deformed) at $1073 \mathrm{~K}$ to reduce their thickness by $20 \%, 40 \%$, or $50 \%$, followed by air-cooling in order to introduce dislocations substructures. A tensile test was conducted at room temperature

$\dagger \quad$ 原稿受理 平成 25 年 5 月 9 日 Received May 9, 2013 (C) 2014 The Society of Materials Science, Japan

* Member : Faculty of Engineering, Kagawa Univ., Hayashi-cho, Takamatsu, 761-0396 Japan

* * Faculty of Engineering, Kagawa Univ., Hayashi-cho, Takamatsu, 761-0396 Japan 
Table 1 Chemical composition of Fe-5\%Si alloy used in this study.

\begin{tabular}{|c|c|c|c|c|c|c|}
\hline $\begin{array}{c}\mathrm{C} \\
\text { mass\% }\end{array}$ & $\begin{array}{c}\mathrm{Si} \\
\text { mass\% }\end{array}$ & $\begin{array}{c}\mathrm{Mn} \\
\text { mass\% }\end{array}$ & $\begin{array}{c}\mathrm{P} \\
\text { mass\% }\end{array}$ & $\begin{array}{c}\mathrm{S} \\
\text { mass\% }\end{array}$ & $\begin{array}{c}\text { sol.Al } \\
\text { mass\% }\end{array}$ & $\begin{array}{c}\mathrm{N} \\
\text { mass\% }\end{array}$ \\
\hline 0.0047 & 4.99 & $<0.01$ & 0.002 & 0.0009 & 0.002 & 0.0022 \\
\hline
\end{tabular}

using an Instron-type testing machine at various strain rates ranging from $10^{-5}$ to $10^{0} / \mathrm{s}$. The gauge length, width and thickness of the test pieces for tensile tests were 6.0, 2.0 and $1.2 \mathrm{~mm}$, respectively. The tensile axis was parallel to the rolling direction (RD). Microstructural observations were conducted using an optical microscope and scanning electron microscope (SEM)equipped with an electron backscattering diffraction (EBSD) system. SEM observations and EBSD measurements were conducted with an accelerating voltage of $15 \mathrm{kV}$. The EBSD measurements were performed with a step size of $0.25 \mu \mathrm{m}$ to clarify the existence of deformation twins.

\section{Results and discussion}

\section{1 Microstructure before tensile test}

Fig. 1 shows the optical microstructures of $0 \%$ rolled (a), 20\% rolled (b), 40\% rolled, (c) and 50\% rolled (d) alloys before tensile test. Figure 2 shows the band contrast maps obtained from the EBSD measurement of $0 \%$ rolled (a), 20\% rolled (b), and 50\% rolled (c) alloys before tensile test. In the band contrast maps, bold and narrow solid lines indicate high-angle boundaries and low-angle boundaries with misorientations between adjacent measurement points are being larger and smaller than $15^{\circ}$, respectively. The boundaries with misorientation smaller than $1.5^{\circ}$ were ignored to eliminate inaccuracy in EBSD analysis. The 0\% rolled alloy had elongated grains along the $\mathrm{RD}$. However, each grain can be regarded as almost fully recrystallized ferritic grain, because there are few low-angle boundaries within the grains. Similar elongated grains were observed from the optical micrographs in rolled alloys by the reduction of $20 \%, 40 \%$ and $50 \%$. In these cases, some low angle boundaries were introduced. This means that the dislocations were introduced within the grains. No deformation twins were observed in any alloy because rolling was conducted at high temperature.
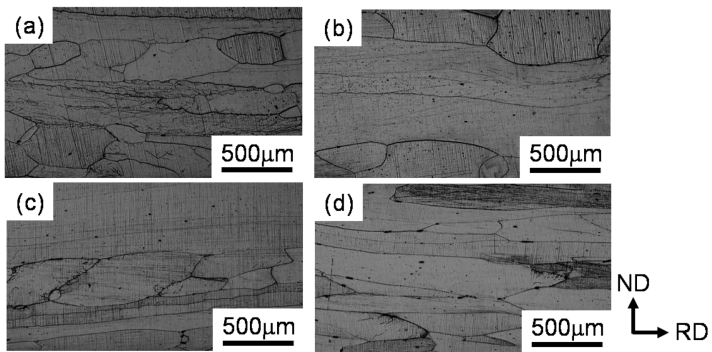

Fig. 1 Optical microstructures of $0 \%$ rolled (a), 20\% rolled (b), 40\% rolled (c), and 50\% rolled (d) alloys. Observations were conducted from the TD.
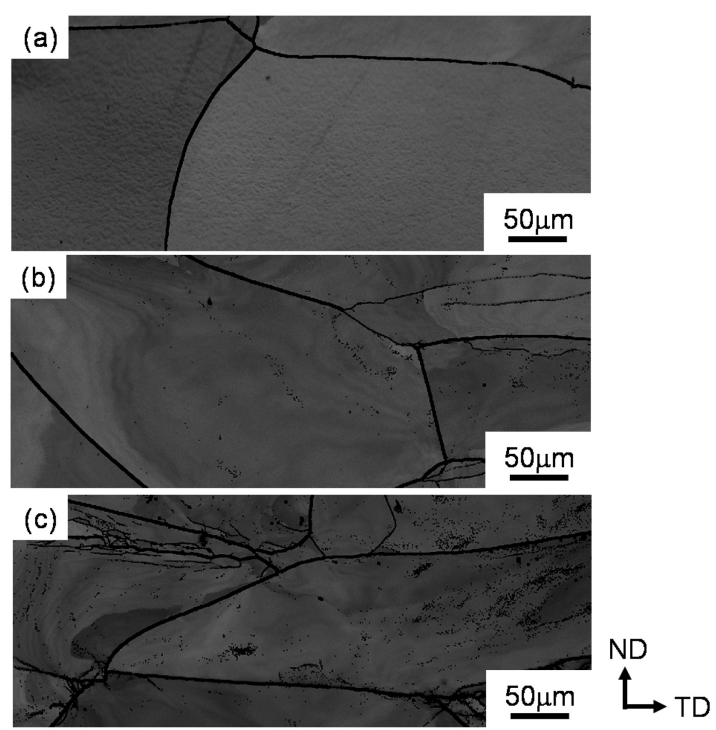

Fig. 2 Band contrast maps obtained from EBSD measurements of $0 \%$ rolled (a), 20\% rolled (b), $50 \%$ rolled (c) alloys, respectively. EBSD analyses were conducted from the RD.

\section{2 Effect of pre-deformation on fracture behavior transition due to strain rate change}

Fig. 3 shows the optical micrographs of the fractured specimen by thickness reduction of $0 \%$ (a), 20\% (b), $40 \%$ (c), and 50\% (d) after the tensile test at a strain rate of $10^{-4} / \mathrm{s}$. The gauge widths as a function of distance
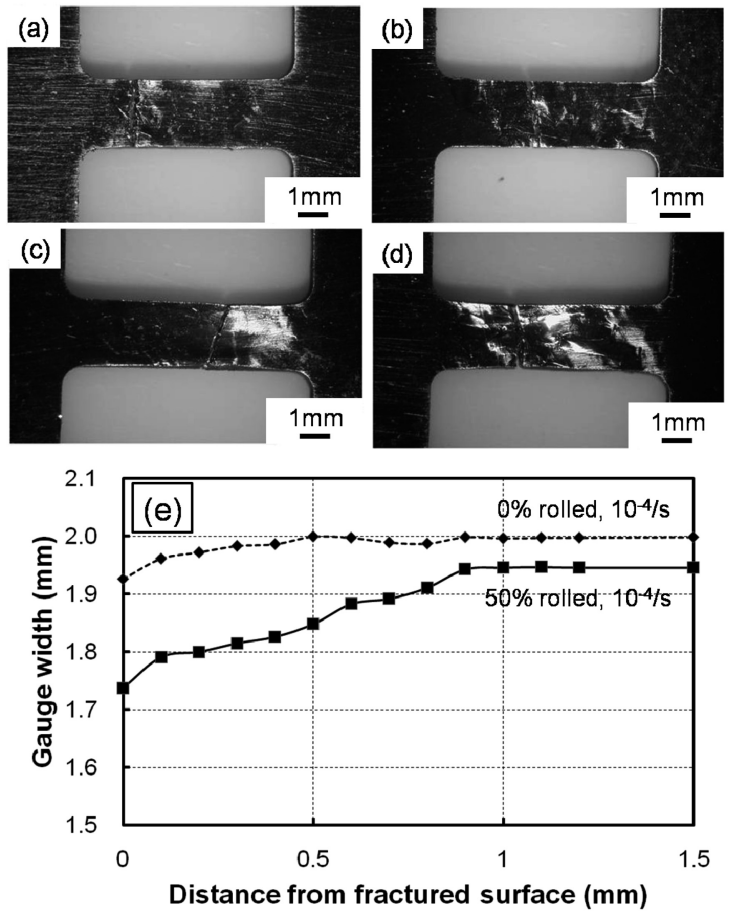

Fig. 3 Appearances of the fractured tensile specimens in $0 \%$ rolled (a), $20 \%$ rolled (b), $40 \%$ rolled (c), and $50 \%$ rolled alloys (d) at the strain rate of $10^{-4} / \mathrm{s}$. The gauge widths as a function of distance from the fractured surface in $0 \%$ and $50 \%$ rolled alloys were plotted in (e) 

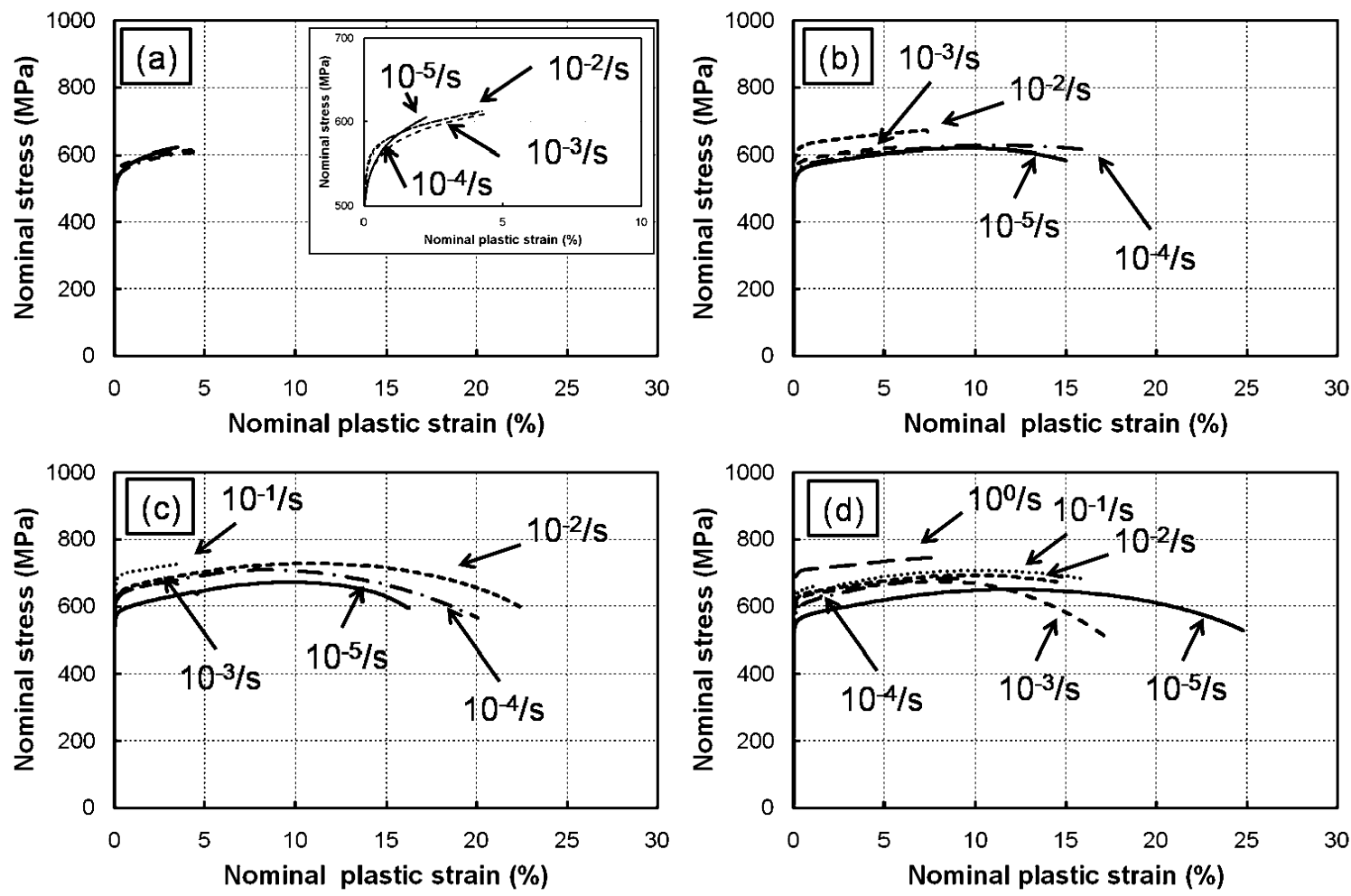

Fig. 4 Nominal stress-nominal plastic strain curves of various strain rates in 0\% rolled (a), 20\% rolled (b), 40\% rolled (c), and 50\% rolled (d) alloys.

from the fractured surface in $0 \%$ and $50 \%$ rolled specimen were measured by measuring microscope and plotted in Fig. 3 (e). All tensile specimens were fractured near the center of the gauge. In addition, $0 \%$ rolled specimen was fractured without any necking and surface change indicating a completely brittle manner. For this specimen, the gauge width near the fracture surface was about 2.0 $\mathrm{mm}$, indicating that the tensile specimen was fractured in completely brittle manner. On the other hand, in the rolled specimen, deep and complicated relief appeared on the surface. The gauge width was decreased as approaching the fracture surface. This means that slight necking due to local plastic deformation was observed near the fractured plane.

Fig. 4 shows the nominal stress-nominal plastic strain curves at various strain rates obtained from $0 \%$ rolled (a), $20 \%$ rolled (b), 40\% rolled (c), and 50\% rolled (d) alloys. The tensile specimen of $0 \%$ rolled alloy broke down without the reduction of nominal stress, (i.e. the localization of plastic deformation) at any examined strain rates. The stress-strain curves similar to those of the $0 \%$ rolled alloy were observed for the $20 \%$ rolled alloy at a strain rate equal or higher than $10^{-3} / \mathrm{s}$. On the other hand, when the $20 \%$ rolled alloy was examined at the strain rate of $10^{-4} / \mathrm{s}$, the elongation with local elongation (deformation after maximum load) was largely recovered. This tendency was also observed in the $40 \%$ and $50 \%$ rolled alloys. The existence of local elongation shown in the stress- strain curves corresponded well with the appearance of necking in the fractured tensile specimens (Fig. 3). This result indicates that the $\mathrm{Fe}-5 \% \mathrm{Si}$ alloys with dislocations by rolling have fracture behavior transition (with/without local elongation) due to the strain-rate change. Similar transition has been observed in fully recrystallized Fe-4\%Si alloy. ${ }^{5)}$, 6) Note that regardless of the fracture manner or occurrence of necking, the elongation becomes larger when rolling reduction increases. This point is discussed later in Fig. 7.

Fig. 5 shows the true stress and work hardening rate as a function of true strain in the $0 \%$ rolled (a) and the $50 \%$ rolled (b) alloys. The work-hardening rate corresponds to the slope of the true stress-true plastic strain curve. In the $0 \%$ rolled alloy, the tensile specimen was fractured before the true stress became equivalent to the work-hardening rate. This means that the specimens were fractured until the maximum stress during the work hardening process. A similar tendency was observed in the $50 \%$ rolled alloy in the case when the specimen was fractured without local elongation (at a strain rate of $10^{-1} / \mathrm{s}$ ). On the other hand, fracture approximately took place when the true stress was equivalent to work hardening rate in the case when the specimen was fractured with local elongation.

Fig. 6 (a-1) and (b-1) shows the SEM images of the fractured plane at a strain rate of $10^{-4} / \mathrm{s}$ in the $0 \%$ rolled (with no local elongation) and 50\% rolled specimen 


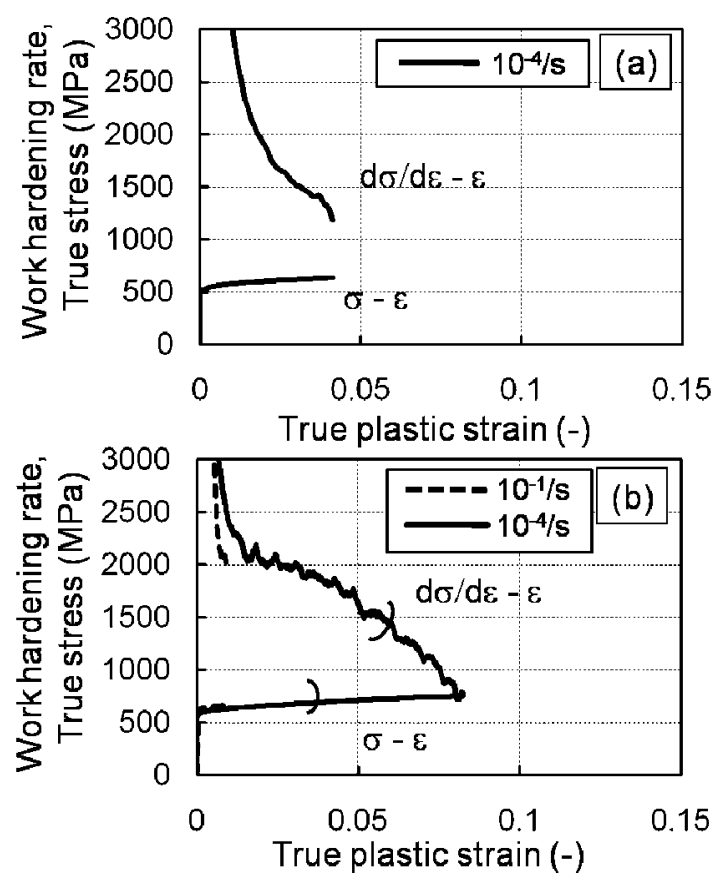

Fig. 5 True stress-true strain curves and work hardening rate-true strain curves in $0 \%$ rolled (a) and 50\% rolled (b) alloys.

(with local elongation), respectively. The SEM low magnification images are also shown in the upper-right part of the images. The tensile specimen of $0 \%$ rolled alloy was fractured in a brittle transgranular cleavage manner without necking because the surface was smooth. The fractured surface of this alloy was also covered with cleavage fractured pattern. In this case, the fractured surface was relatively rough with slight necking, indicating that the specimen was fractured in a completely brittle intergranular cleavage manner. It was also found that the fractured surfaces of both alloys had many cracks as indicated by arrows. However, the length of the crack on the as-received sample (larger than a few hundred $\mu \mathrm{m}$ ) was somewhat larger than that of the $50 \%$ rolled specimen (approximately a few hundred $\mu \mathrm{m}$ ). This difference probably indicates that the propagation of the cleavage crack can be suppressed by the dislocation microstructure introduced by hot rolling. High-magnification SEM images of Fig. 6 (a-1) and (b-1) are shown in Fig. 6 (a-2) and (b-2), respectively. From Fig. 6 (a-2), many band-like contrasts were observed on the fracture surface. These contrasts were considered to be deformation twins, which is discussed later in Fig. 8. This indicates that fracture with no local elongation is associated with deformation twins and that twin boundaries act as a crack initiation site. ${ }^{16)}$ On the other hand, fewer deformation twins were observed on the fractured surface in the $50 \%$ rolled alloy with local elongation. In this case, it is considered that dislocations piled up against obstacles, such as grain boundary, leads to initiation of cleavage fracture ${ }^{7)}$
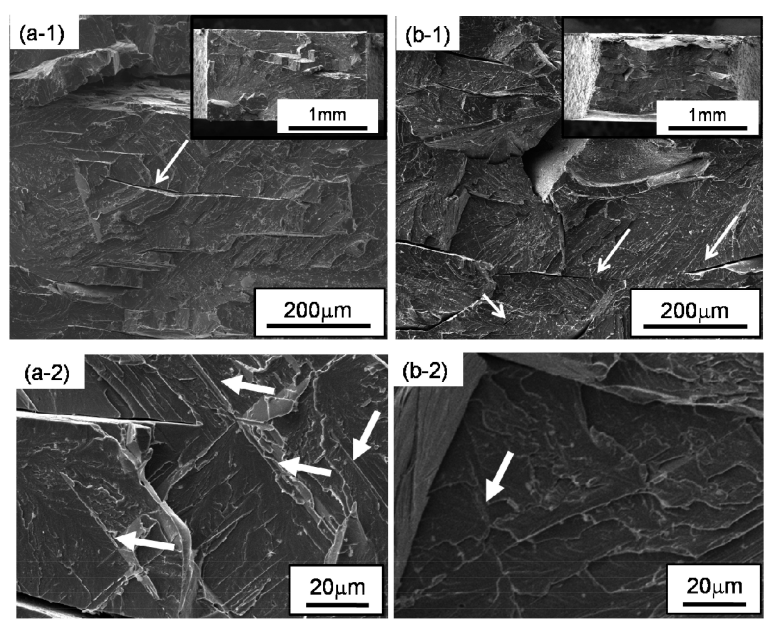

Fig. 6 SEM secondary electron images of the fractured tensile specimen at a strain rate of $10^{-4} / \mathrm{s}$ in the $0 \%$ rolled (a) and $50 \%$ rolled (b) alloy. Highmagnification images of (a-1) and (b-1) are shown in (a-2) and (b-2), respectively.

and that the crack initiation site in Fe-5\%Si alloy was changed with/without local elongation. It is difficult to detect a change of the fracture manner from brittle to ductile by conventional fractography clearly because all tensile specimen examined fractured in a brittle manner. Alternatively, in this study, the fracture behavior was classified by the existence or non existence of local elongation.

Fig. 7 summarizes the relationship between the strain rate and tensile properties of the $\mathrm{Fe}-5 \% \mathrm{Si}$ alloys with various microstructures. The $0.2 \%$ proof strength (a) and tensile stress (b) tended to increase with the increasing of the reduction and strain rate. This strength is likely to be caused by the dislocations introduced by rolling. The total elongation (c) tended to increase with the increase of the reduction by the rolling when the data were compared at the same strain rate. This indicates that the introduction of dislocation substructures enhances the ductility of Fe-high Si alloy. In addition, the rolled alloys showed discontinuous large drops in total elongation, as denoted by the arrows in Fig. 7. For example, the total elongation in the $20 \%$ rolled alloy decreased drastically at a strain rate between $10^{-4} / \mathrm{s}$ to $10^{-3} / \mathrm{s}$. The strain rate at which this drop takes place corresponds well with the strain rate at which local elongation disappeared, as shown in Fig. 4. Thus, the strain rate at which the elongation drops drastically can be regarded as a threshold value that indicates the transition of the fracture behavior. The threshold strain rate increased with the increasing of the reduction. It is occasionally considered that fracture process is controlled by thermally activated motion of dislocation. In this sense, low-temperature deformation is equivalent to high strain rate deformation. 

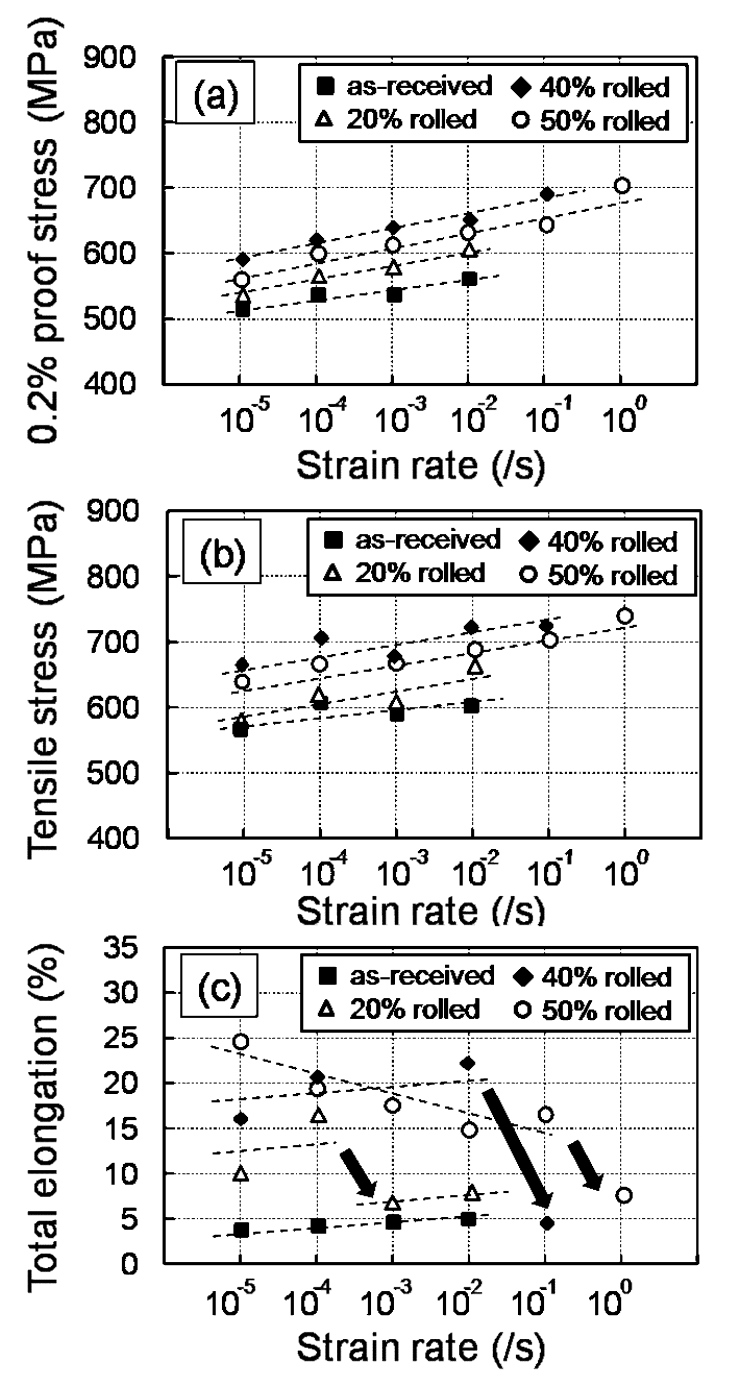

Fig. $7 \quad 0.2 \%$ proof stress (a), tensile stress (b) and total elongation (c) of $\mathrm{Fe}-5 \% \mathrm{Si}$ alloys with various rolling reductions at various strain rates.

The higher strain rate at which ductile-brittle transition occurs corresponds with the lower ductile-brittle transition temperature. It is also considered that the transition temperature is a benchmark of toughness in Fe-Si alloy. Consequently, it can be mentioned that the introducing of dislocation substructure by larger pre-strain improves both ductility and toughness of the Si steel effectively.

It is generally considered that brittle fracture with no plastic deformation takes place when stress reaches the cleavage fracture stress determined by the composition $^{17)}$ and the microstructure. However, the fracture in brittle manner in all $\mathrm{Fe}-5 \% \mathrm{Si}$ alloys occurs after some plastic deformation. This means that the brittle fracture in Si steel cannot be explained by the conventional comparison of the fracture and yield stresses, ${ }^{18)}$ because the influence of the deformation microstructure, such as dislocation substructure and deformation twins evolved by plastic deformation before fracture, can be predicted. Fig. 8 (a) and (b) shows the SEM backscattering electron images of the fractured tensile specimen at $10^{-4} / \mathrm{s}$ in $0 \%$ rolled
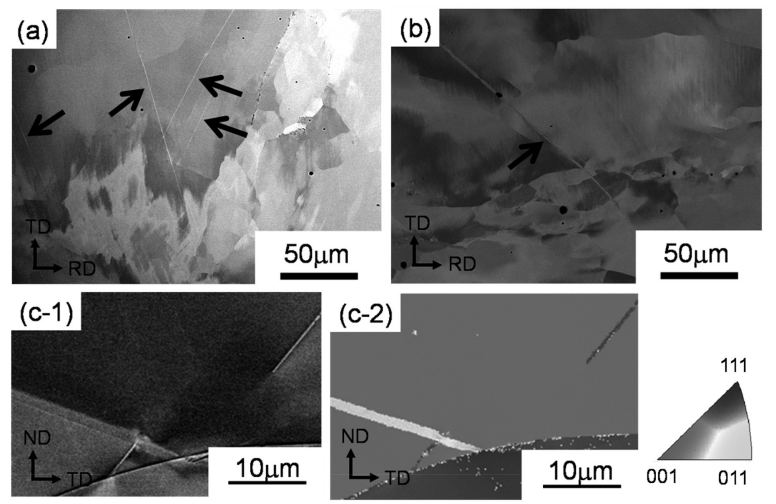

Fig. 8 SEM backscattered images of the fractured tensile specimen in the $0 \%$ rolled (a) and $50 \%$ rolled (b) alloy at a strain rate of $10^{-4} / \mathrm{s}$. SEM backscattered image and crystal-orientation map taken of the same area obtained from a fractured specimen were also shown. ${ }^{19)}$

(with no local elongation) and 50\% rolled (with local elongation) alloy. Band-like features with a thickness in the order of a micrometer across the grain were identified. Previous study of our group ${ }^{19)}$ reported that similar band-like features identified by SEM backscattered images from a fractured specimen in $\mathrm{Fe}-5 \% \mathrm{Si}$ alloy and that these were determined to be deformation twins because the crystal orientation of this area is quite different from that of the grain, and the boundaries between them were characterized to be twin boundaries of $\sum 3$ type (Fig. 8 (c)) . Therefore, these features shown in Fig. 8 (a) and (b) were classified to be deformation twins. As shown in these figures, both fractured tensile specimens contain deformation twins (as indicated by arrows in Fig. 8 (a) and (b)) near the fractured plane, however, the number density of twins in the $0 \%$ rolled alloy was much higher than that of the 50\% rolled alloy. This corresponds with the SEM observation of the cracks, shown in Fig. 6. This indicates that the initiation of the twinning was inhibited by the dislocation substructure as shown in Fig. 6 (a-2) and (b-2). Some researchers ${ }^{4), 13)}$ suggest that dislocation substructures such as mobile dislocations introduced by predeformation improve the ductility of Fe-high Si alloys. Unfortunately, it has not been clarified if dislocations induced by rolling were mobile dislocations. However, our obtained results indicate that the dislocation substructures evolved by rolling suppressed the initiation of twinning.

\section{Conclusions}

The fully recrystallized Fe-5\%Si alloys were fractured in the brittle manner at different strain rates and the transition strain rate was not found. The Fe-5\% Si alloys with dislocations introduced by rolling exhibited fracture behavior transition due to strain-rate change. All rolled alloys were fractured with necking at slower strain rates. When the strain rate became higher than the threshold 
value, the local elongation (necking) disappeared and the fracture manner changed to brittle. The threshold strain rate is higher with increasing of the rolling reduction. The fractography and microstructures in the fractured samples indicated that dislocations substructures are effective for inhibiting the initiation of the deformation twins. Consequently the enhancement of both toughness and ductility in Fe-high Si alloy can be achieved.

This study was financially supported by JSPS KAKENHI Grant Number 23760700 and by the fund for Kagawa University Young Scientists 2010. The author gratefully appreciates all of the support received.

\section{References}

1) R. M. Bozorth (Eds.), "Ferromagnetism”, D. Nostrand Co. Inc., New Jersey, p.77 (1951).

2 ) K. Matsumura and B. Fukuda, "Recent developments of non-oriented electrical steel sheets”, IEEE Transactions on Magnetics, Vol.20, pp.1533-1538 (1984).

3 ) K. F. Ha, C. Yang and J. S. Bao, "Effect of dislocation density on the ductile-brittle transition in bulk Fe-3\%Si single crystals”, Scripta Metallurgica et Materialia, Vol.30, pp.1065-1070 (1994).

4 ) N. Narita, K. Higashida and H. Kita, "Brittle fracture and twinning at low temperatures in Fe-Si alloy crystals”, Journal of the Society of Materials Science, Vol.36, pp.854-860 (1987).

$5)$ T. Mizuguchi, R. Oouchi, R. Ueji, A. Takemura and K. Kunishige, "Fracture mechanism transition due to strain rate change in Si steels", Proceedings of the 2nd International Symposium on Steel Science 2009 pp.257-260 (2010).

$6)$ T. Mizuguchi, R. Oouchi, R. Ueji, Y. Tanaka and K. Shinagawa, "Effect of Si content on fracture behaviour change by strain rate in $\mathrm{Si}$ steels”, Materials Science Forum, Vol.654-656, pp.1303-1306 (2010).

7 ) T. Smida and J. Bosansky, "Deformation twinning and its possible influence on the ductile brittle transition temperature of ferritic steels", Materials Science and Engineering A, Vol.287, pp.107-115 (2000).
8 ) F. Sorbello, P. E. J. Flewitt, G. Smith and A. G. Crocher, "The role of deformation twins in brittle crack propagation in iron-silicon steel”, Acta Materialia, Vol.57, pp.2646-2656 (2009).

$9)$ A. T. Churchman and A. H. Cottrell, "Yield phenomenon and twinning in $\alpha$-iron”, Nature Vol.167, pp.943-945 (1951).

10) J. J. Cox, G. T. Horne and R. F. Mehl, "Slip, twinning and fracture in single crystals of iron", Transactions of the American Society for Metals, Vol.49, pp.118-131 (1957).

11) W. D. Biggs and P. L. Pratt, "The deformation and fracture of alpha-iron at low temperatures", Acta Metallurgica, Vol.6, pp.694-703 (1958).

12) T. L. Altshuler and J. W. Christian, "Low temperature twinning in pure iron”, Acta Metallurgica, Vol.14, pp.903-908 (1967).

13) S. Ikeda and T. Takeuchi, "Twinning stress in pre-strained iron single crystals", Journal of the Physical Society of Japan, Vol.22, No.4, pp.1036-1041 (1967)

14) A. Uenishi and C. Teodosiu, "Solid solution softening at high strain rates in Si- and/ or Mn-added interstitial free Steels”, Acta Materialia, Vol.51, pp.4437-4446 (2003).

15) B. Aronsson and L. Granas, "Strain rate sensitivity and ductile-brittle behavior of polycrystalline $\mathrm{Fe}-\mathrm{Si}$ alloys with $2.5,3.5$, and 4.5 Wt Pct Si”, Metallurgical Transactions, Vol.2, No.4, pp.1087-1093 (1971).

16) J. Bosansky and T. Smida, "Deformation twins - probable inherent nuclei of cleavage fracture in ferritic steels", Materials Science and Emgineering A, Vol.323 pp.198-205 (2002).

17) R. T. Qu and Z. F. Zhang, "A universal fracture criterion for high-strength materials”, Scientific Reports, Vol.3, Article No.1117, 6 pages (2013)

18) H. Kimura, "Zairyoukyoudo no kangaekata", Agne, Tokyo, pp.307-315 (1997).

19) T. Mizuguchi, K. Ikeda, N. Karasawa and Y. Tanaka, "Effects of temperature and strain rate on stress-strain relationship and deformation twinning in $\mathrm{Fe}-5 \% \mathrm{Si}$ alloy", Materials Science Forum (2013) accepted. 